\title{
Effect of Tween 80 on the Morphology and Physiology of Lactobacillus salivarius Strain IV CL-37 Grown in a Chemostat under Glucose Limitation
}

\author{
By NICHOLAS A. JACQUES, ${ }^{1}+$ LYN HARDY, ${ }^{1}$ KENNETH W. KNOX ${ }^{1 *}$ \\ AND ANTHONY J. WICKEN ${ }^{2}$ \\ ${ }^{1}$ Institute of Dental Research, United Dental Hospital, Sydney, \\ New South Wales 2010, Australia \\ 2 School of Microbiology, University of New South Wales, Kensington, \\ New South Wales 2033, Australia
}

(Received 31 October 1979; revised 25 January 1980)

\begin{abstract}
The effect of Tween 80 on Lactobacillus salivarius strain IV CL-37 growing in a chemostat under various conditions was investigated. The organisms could grow under glucose limitation in the absence of Tween 80 at pH 6.0 or lower anaerobically but not aerobically. Aerobic growth under glucose limitation and in the presence of Tween 80 occurred in complete MRS medium but not in the dialysable fraction of MRS medium. The morphology of cells differed from coccal to filamentous and branched structures according to the growth condition. The possible effect of Tween 80 on membrane components was examined by estimating the cellular and extracellular lipoteichoic acid contents. In both batch and continuous culture the amounts of cellular lipoteichoic acid were inversely related to the amount of Tween 80 whereas the amounts of extracellular lipoteichoic acid were influenced by other factors in addition to Tween 80 .
\end{abstract}

\section{INTRODUCTION}

Lactobacilli represent a variable but generally low proportion of the flora of dental plaque. Their acidogenic and aciduric properties have evoked interest in their potential role in dental caries but definitive evidence has been lacking. It was recently reported, however, that three human isolates of lactobacilli induced caries in hamsters harbouring a mixed oral microbial flora (Fitzgerald et al., 1980). One of these strains, designated IV CL-37, came from a site in the patient where plaque samples consistently contained lactobacilli prior to and during caries development and it has been identified as Lactobacillus salivarius (Jacques et al., 1980).

During further studies on the growth of strain IV CL-37 it was noted that the requirement for Tween 80 depended on the $\mathrm{pH}$ of the medium. As several lactobacilli require Tween 80 for growth, it is included in the frequently used MRS medium (de Man et al., 1960). Because of the greater control over growth conditions that can be achieved in the chemostat, a study was therefore undertaken on the effect of variations in medium composition, including Tween 80 content, $\mathrm{pH}$, generation time, and aerobic or anaerobic conditions on the properties of this strain of $L$. salivarius. In particular, variations in morphology were monitored because of the organism's observed pleomorphism. Variations in lipoteichoic acid content were determined because of the known effect of growth conditions on lipoteichoic acid production (Jacques et al., 1979a, b).

$\dagger$ Present address: Laboratory of Microbiology and Immunology, National Institute of Dental Research, National Institutes of Health, Bethesda, Maryland 20205, U.S.A. 


\section{METHODS}

Organisms. Strains L. salivarius subsp. salivarius ATCC 11741, L. salivarius subsp. salicinus ATCC 11742 and $L$. salivarius IV CL-37 were available from previous studies (Jacques et al., 1980); strain IV CL-37 had been kindly supplied by Dr R. J. Fitzgerald, Veterans Administration Hospital, Miami, Fla, U.S.A.

Media. Batch cultures of organisms were routinely grown at $37^{\circ} \mathrm{C}$ in standard MRS medium (de Man et al., 1960) containing $2 \%(\mathrm{w} / \mathrm{v})$ glucose and $0.1 \%(\mathrm{v} / \mathrm{v})$ Tween $80\left(\right.$ i.e. $730 \mu \mathrm{g} \mathrm{ml}^{-1}$ ), and checked for purity by growth on MRS agar plates. Under both conditions the cells were short rods, which will be referred to as their normal morphology in contradistinction to the variations apparent under other growth conditions.

MRS medium was modified by decreasing the glucose content to $0.5 \%(\mathrm{w} / \mathrm{v})$, deleting Tween 80 and adding $\mathrm{KH}_{2} \mathrm{PO}_{4} / \mathrm{Na}_{2} \mathrm{HPO}_{4}$ buffer, $\mathrm{pH} 6.0$ or 7.0 , to give $0.2 \mathrm{M}$; by this means the change in $\mathrm{pH}$ during growth was minimized and the final $\mathrm{pH}$ of cultures commencing at $\mathrm{pH} 7 \cdot 0$ remained about 6.0 . Tween 80 was added to individual tubes to give $50,100,150,250$ and $750 \mu \mathrm{g} \mathrm{ml}^{-1}$. Tween 80 (polyoxyethylene sorbitan mono-oleate) was obtained from Selbys Scientific Ltd, Sydney, Australia; the corresponding monolaurate (Tween 20), monopalmitate (Tween 40) and monostearate (Tween 60) esters were kindly supplied by Mrs A. M. Bersten, University of Sydney (Packer \& Bersten, 1977).

The growth of organisms in continuous culture at $37^{\circ} \mathrm{C}$ employed MRS medium, which had been sterilized by autoclaving 101 amounts for $1 \mathrm{~h}$ at $121^{\circ} \mathrm{C}$, or in a modified MRS medium. In the latter case the organic components of the medium were separated into non-diffusible and diffusible fractions on an Amicon H1 P10 Hollow Fiber Dialyser (model RC2, Amicon Corp., Lexington, Mass., U.S.A.); the medium was then prepared from the diffusible fraction and sterilized by membrane filtration $(0 \cdot 2 \mu \mathrm{m}$ porosity). In each case glucose was present at $10 \mathrm{~g}^{-1}$ to give carton-limited growth. Tween 80 was added at an appropriate concentration.

Growth conditions. Cultures in phosphate-buffered MRS medium were incubated anaerobically for $16 \mathrm{~h}$ and growth was measured turbidimetrically at $600 \mathrm{~nm}$.

Lipoteichoic acid production was followed in organisms grown in MRS medium in a Multigen fermenter with automatic pH control (New Brunswick Scientific Co., New Brunswick, N.J., U.S.A.) and gassed with $95 \% \mathrm{~N}_{2} / 5 \% \mathrm{CO}_{2}\left(200 \mathrm{ml} \mathrm{min}^{-1}\right)$. A portion of the culture was withdrawn at the end of exponential phase and the remainder was collected $18 \mathrm{~h}$ after entering stationary phase.

Continuous culture was in a Bio-Flo chemostat (model C30, New Brunswick Scientific Co.) gassed with either air $\left(1000 \mathrm{ml} \mathrm{min}^{-1}\right)$ or $95 \% \mathrm{~N}_{2} / 5 \% \mathrm{CO}_{2}\left(200 \mathrm{ml} \mathrm{min}^{-1}\right)$; the procedures for monitoring growth were described previously (Jacques et al., 1979b). The pH was maintained to within $\pm 0.05 \mathrm{pH}$ units by automatic

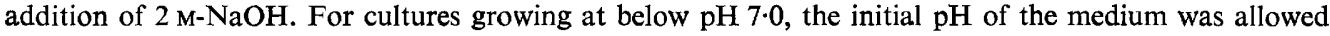
to fall to the desired value by the natural production of acid by the bacteria. Organisms were grown at dilution rates $(D)$ of 0.05 and $0.2 \mathrm{~h}^{-1}$ and were maintained within a standard deviation of $\pm 1.5 \%$. Where samples were taken for morphological examination or analysis of lipoteichoic acid content, cultures were allowed to equilibrate for seven mean generation times (five volume changes) before samples were collected for analysis. Steady state conditions were assumed to be occurring when the $A_{600}$ value of the culture was constant over at least $24 \mathrm{~h}$, whereas a continual decrease in $A_{600}$ was indicative of 'wash-out' and/or lysis of organisms. 'Wash-out' showed that organisms could not grow at the imposed generation time and lysis was detected by the aberrant appearance of Gram-stained cultures.

Cultures from the chemostat were also examined by plating on MRS agar and by testing their physiological characteristics using the API-System-Lactobacillus (Analytab Products, Plainview, N.Y., U.S.A.).

Serological methods. Lipoteichoic acid was detected by its reactivity with antiserum prepared against L. casei lipoteichoic acid (rabbit 409); such antisera can be used to detect different lipoteichoic acids because the antibodies are specific for the common glycerol phosphate backbone (Markham et al., 1975). The lipoteichoic acid content of organisms was estimated by extracting the cells with hot aqueous phenol, dialysing the aqueous phase and examining the extract by rocket immunoelectrophoresis (Jacques et al., 1979b). The corresponding culture fluids were dialysed, concentrated, and also examined by rocket immunoelectrophoresis (Jacques et al., 1979b). The results were standardized by expressing the rocket heights for cell extracts relative to $10 \mu \mathrm{g}$ dry wt extracted cells and for culture fluids relative to the volume of culture fluid corresponding to $10 \mu \mathrm{g}$ organisms. Rocket heights depend on the amount of antibody present and are therefore not absolute. However, all studies were carried out on the same batch of serum and with appropriate controls in all experiments, and the results shown in a particular table or figure were all from the same plate.

The sensitization of erythrocytes with the lipoteichoic acid component of culture fluid and the subsequent determination of the haemagglutination and culture fluid titres were performed as described previously (Markham et al., 1975). The culture fluid titre is defined as the greatest dilution that will fully sensitize erythrocytes and is a measure of the lipoteichoic acid content, whereas rocket immunoelectrophoresis will also detect deacylated lipoteichoic acid. 
Table 1. Effect of Tween 80 on the growth of Lactobacillus salivarius strains at initial $p H$ values of $6 \cdot 0$ and $7 \cdot 0$

Growth was followed turbidimetrically at $600 \mathrm{~nm}$.

\begin{tabular}{|c|c|c|c|c|c|c|}
\hline \multirow{3}{*}{$\begin{array}{l}\text { Tween } 80 \\
\left(\mu \mathrm{g} \mathrm{ml}^{-1}\right)\end{array}$} & \multicolumn{6}{|c|}{$A_{600}$} \\
\hline & \multicolumn{2}{|c|}{ L. salivarius subsp. salivarius } & \multicolumn{2}{|c|}{ L. salivarius subsp. salicinus } & \multicolumn{2}{|c|}{ L. salivarius strain IV CL-37 } \\
\hline & pH 6.0 & $\mathrm{pH} 7.0$ & pH 6.0 & pH 7.0 & pH 6.0 & pH 7.0 \\
\hline 0 & 0.90 & 0.40 & 0.90 & 0.63 & 0.95 & $0 \cdot 20$ \\
\hline 50 & $1 \cdot 15$ & 0.83 & $1 \cdot 30$ & 0.78 & 1.28 & 0.23 \\
\hline 100 & $1 \cdot 35$ & 0.93 & 1.40 & 0.83 & 1.38 & 0.30 \\
\hline 150 & $1 \cdot 23$ & 1.00 & $1 \cdot 38$ & 0.90 & $1 \cdot 33$ & 0.40 \\
\hline 250 & 1.28 & 1.00 & $1 \cdot 40$ & 0.90 & 1.33 & 0.90 \\
\hline 750 & 1.20 & 0.98 & 1.38 & 1.05 & 1.28 & 1.20 \\
\hline
\end{tabular}

Table 2. Determination of ability of L. salivarius strain IV CL-37 to maintain growth in the presence or absence of Tween 80 at different $p H$ values Organisms were grown in continuous culture under glucose limitation at $D=0.05 \mathrm{~h}^{-1}$ and main-
tenance of growth was determined as described in Methods.

$\begin{array}{llcl}\text { Medium } & \text { Conditions } & \begin{array}{c}\text { Tween } 80 \\ \left(730 \mu \mathrm{g} \mathrm{ml} \mathbf{l}^{-1}\right)\end{array} & \begin{array}{l}\mathrm{pH} \text { range } \\ \text { of growth }\end{array} \\ \text { MRS } & \text { Aerobic } & + & 5 \cdot 0-7 \cdot 0 \\ & \text { Anaerobic } & + & \text { No growth } \\ & & - & 5 \cdot 0-7 \cdot 0 \\ \text { Dialysed MRS } & \text { Aerobic } & + & 5 \cdot 0-7 \cdot 0 \\ & & - & \text { No growth } \\ & \text { Anaerobic } & + & 5 \cdot 0-7 \cdot 0 \\ & & - & 5 \cdot 0-7 \cdot 0\end{array}$

RES ULTS

Requirement of Tween 80 for growth in batch culture

Growth of strain IV CL-37 was very poor in MRS medium lacking Tween 80 and was also poor if Tween 80 was replaced with $0 \cdot 1 \%(\mathrm{v} / \mathrm{v})$ of Tween 20,40 or 60 . With L. salivarius subsp. salivarius and subsp. salicinus, growth at pH 6.0 was only slightly impaired in the absence of Tween 80 , whereas at $\mathrm{pH} \mathrm{7.0}$ growth was considerably decreased in the absence of Tween 80 and $150 \mu \mathrm{g}$ Tween $80 \mathrm{ml}^{-1}$ was required for maximal growth (Table 1). For strain IV CL-37, a similar effect was obtained at $\mathrm{pH} 6.0$ but the effect at $\mathrm{pH} 7.0$ was even more marked and $750 \mu \mathrm{g}$ Tween $80 \mathrm{ml}^{-1}$ was required for maximal growth. More detailed studies on the effect of different growth conditions on Tween 80 requirement were therefore carried out on strain IV CL-37.

\section{Requirement of Tween 80 for growth of strain IV CL-37 in continuous culture}

The ability of organisms to maintain growth under glucose limitation in the absence of Tween 80 was examined under a variety of conditions, namely variation in gaseous environment (aerobic or anaerobic), $\mathrm{pH}$ of growth (generally $5 \cdot 0,6.0$ or $7 \cdot 0$ ), or dilution rate $(0.05$ or $\left.0 \cdot 2 \mathrm{~h}^{-1}\right)$. Under each of the conditions examined, growth in the presence of $730 \mu \mathrm{g}$ Tween $80 \mathrm{ml}^{-1}(0 \cdot 1 \%, \mathrm{v} / \mathrm{v})$ was compared with that in its absence by following the absorbance of the culture and the appearance of Gram-stained organisms. Even at $D=0.05 \mathrm{~h}^{-1}$ any changes leading to 'wash-out' were generally apparent within $8 \mathrm{~h}$ of the change of growth conditions and could be confirmed within $24 \mathrm{~h}$. The results obtained at $D=0.05 \mathrm{~h}^{-1}$ are 


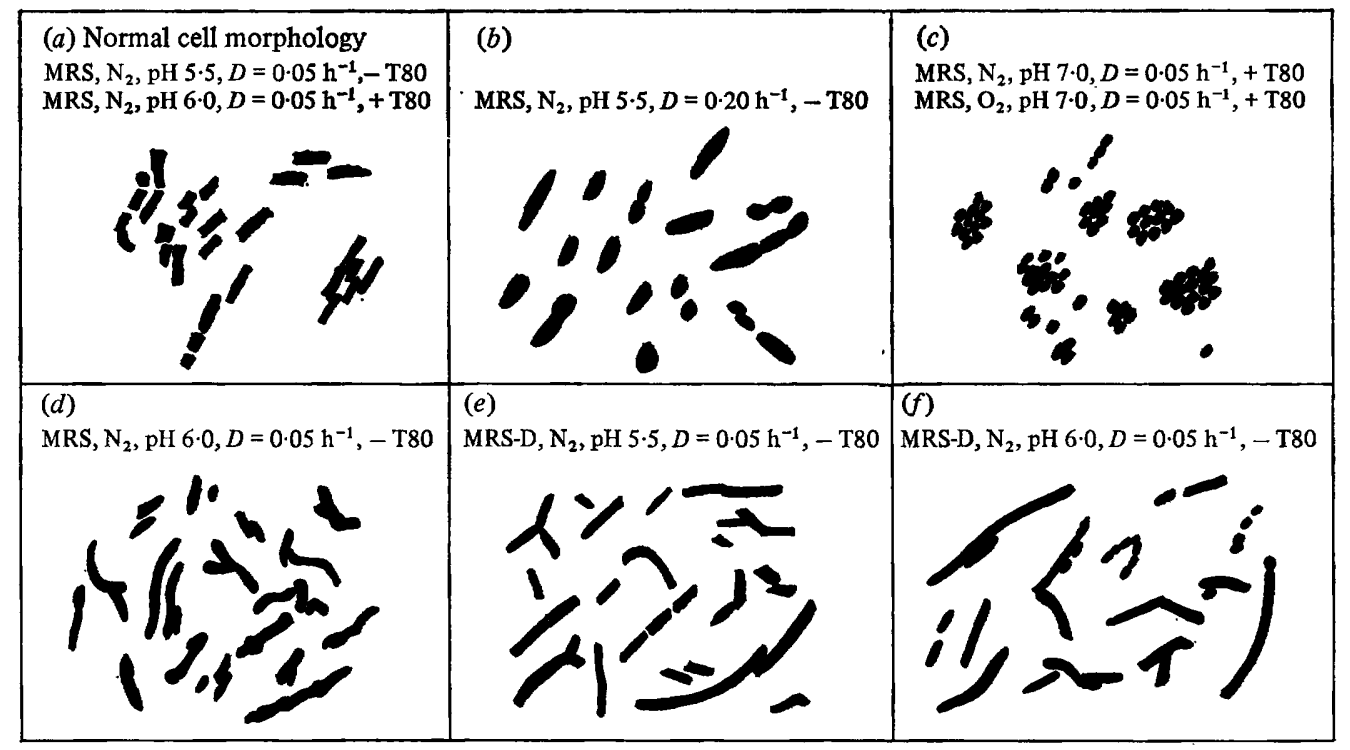

Fig. 1. Effect of growth conditions on the morphology of $L$. salivarius strain IV CL-37. The normal morphology of organisms grown on agar was compared with that of organisms growing in continuous culture under glucose limitation. The various modifications of culture conditions are identified by designating the medium as either complete (MRS) or dialysed (MRS-D), the environment as either aerobic $\left(\mathrm{O}_{2}\right)$ or anaerobic $\left(\mathrm{N}_{2}\right)$, the $\mathrm{pH}$ of growth, the dilution rate as either $0.05 \mathrm{~h}^{-1}$ or $0.2 \mathrm{~h}^{-1}$, and the presence $(+)$ or absence $(-)$ of Tween 80 (T80). Cells were stained with Gram's stain and the drawings depict a typical field of view under the microscope.

summarized in Table 2. Similar results were obtained for cultures examined at $D=0 \cdot 2 \mathrm{~h}^{-1}$; at this dilution rate organisms in MRS medium lacking Tween 80 and under anaerobic conditions at $\mathrm{pH} 6.5$ grew for $2 \mathrm{~d}$ (about 14 generations) but then commenced to lyse.

The relation of $\mathrm{pH}$ of growth to Tween 80 requirement was further examined by adding Tween 80 at $1 \mathrm{mg} \mathrm{ml}^{-1}$ to a culture growing anaerobically at $\mathrm{pH} 6.0$ and $D=0.05 \mathrm{~h}^{-1}$, adjusting the $\mathrm{pH}$ to 7.0 and then supplying the organisms with MRS medium devoid of Tween 80. After $4 \mathrm{~d}$ of culturing (seven generations), the cellular morphology had changed to very long rods and cell lysis followed on the sixth day. Similar results were obtained when organisms were grown aerobically in MRS medium at $\mathrm{pH} 7 \cdot 0$. It can be calculated from the dilution rate that the concentration of Tween 80 after $4 \mathrm{~d}$ would have been diluted to approximately $30 \mu \mathrm{g} \mathrm{ml}^{-1}$ even if it were not being utilized for growth.

\section{Effect of growth conditions in continuous culture on cell morphology}

The cell morphology of strain IV CL-37 growing in MRS medium and dialysed MRS medium under the different continuous culture conditions described above is shown in Fig. 1. The differences observed were due to the immediate growth conditions as cells subsequently grown on MRS agar showed normal colony and cell morphology, and no changes in physiological characteristics could be detected with the API-System-Lactobacillus. From Fig. 1, cell morphology is evidently influenced by the following changes in growth conditions: (1) Changing the dilution rate from $0.05 \mathrm{~h}^{-1}(a)$ to $0.2 \mathrm{~h}^{-1}(b)$ for organisms growing in the absence of Tween 80 . (2) Increasing the $\mathrm{pH}$ from $6.0(a)$ to $7.0(\mathrm{c})$ for organisms growing anaerobically with Tween 80 ; at $\mathrm{pH} 7.0(\mathrm{c})$ cell morphology was similar under both aerobic and anaerobic conditions. (3) Adding Tween 80 to cultures growing anaerobically at $\mathrm{pH} 6.0$ $(a)$, where the morphology contrasts with that in the absence of Tween $80(d)$. (4) Growing organisms anaerobically in dialysed MRS medium at pH 5.5 $(e)$ or $6.0(f)$ in the absence 
Table 3. Effect of Tween 80 content of medium on the lipoteichoic acid(LTA) content of cells and culture fluid from batch-grown L. salivarius strain IV CL-37

Estimates of the amounts of lipoteichoic acid were obtained by rocket immunoelectrophoresis (RIE) and by determining the culture fluid (CF) titre.

\begin{tabular}{|c|c|c|c|c|}
\hline \multirow[b]{2}{*}{ Growth phase } & \multirow[b]{2}{*}{$\begin{array}{l}\text { Tween } 80 \\
\left(\mu \mathrm{g} \mathrm{ml}^{-1}\right)\end{array}$} & \multicolumn{2}{|c|}{ RIE estimation [cm $\left.(10 \mu \mathrm{g} \text { cells })^{-1}\right]$} & \multirow[b]{2}{*}{$C F$ titre } \\
\hline & & $\begin{array}{c}\text { Cellular } \\
\text { LTA }\end{array}$ & $\begin{array}{c}\text { Extracellular } \\
\text { LTA }\end{array}$ & \\
\hline Exponential & $\begin{array}{l}220 \\
730\end{array}$ & $\begin{array}{l}2 \cdot 8 \\
0 \cdot 8\end{array}$ & $\begin{array}{l}1 \cdot 6 \\
1 \cdot 2\end{array}$ & $\begin{array}{l}7 \cdot 5 \\
7 \cdot 5\end{array}$ \\
\hline Stationary & $\begin{array}{l}220 \\
730\end{array}$ & $\begin{array}{l}1 \cdot 7 \\
1 \cdot 7\end{array}$ & $\begin{array}{l}9 \cdot 8 \\
5 \cdot 5\end{array}$ & $\begin{array}{l}60 \\
27\end{array}$ \\
\hline
\end{tabular}

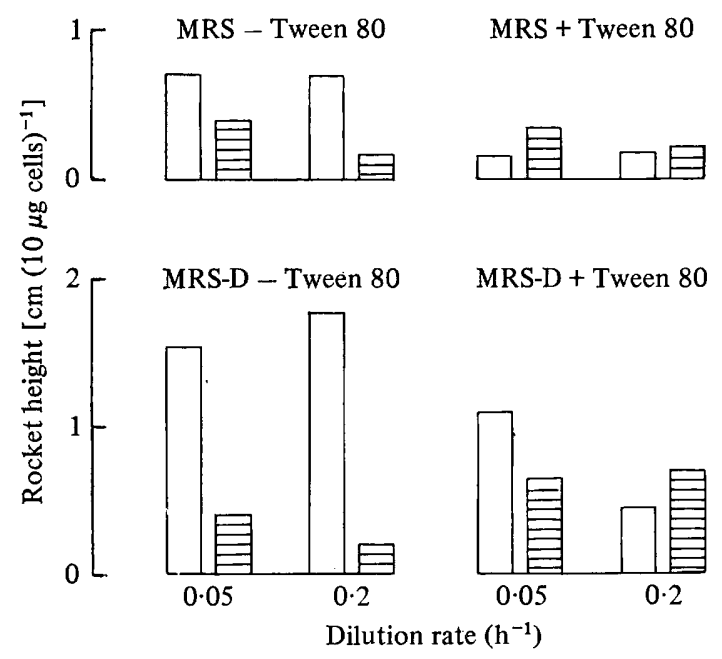

Fig. 2. Effect of growth conditions on lipoteichoic acid production by $L$. salivarius strain IV CL-37. Organisms were grown anaerobically at pH 6.0 in continuous culture under glucose limitation at dilution rates of either $0.05 \mathrm{~h}^{-1}$ or $0.2 \mathrm{~h}^{-1}$ in complete (MRS) or dialysed (MRS-D) medium. Where indicated, Tween 80 was present at $1 \mathrm{mg} \mathrm{m}^{-1}$. The lipoteichoic acid contents of organisms (open bars) and the corresponding culture fluids (shaded bars) were estimated by rocket immunoelectrophoresis.

of Tween 80 , where the morphology contrasts with that obtained in complex medium $(a)$; the branched appearance in (e) was shown by 2 to $3 \%$ of cells in the culture.

\section{Effect of growth conditions on formation of lipoteichoic acid}

The possible effect of Tween 80 on the production of lipoteichoic acid by batch-grown cultures of strain IV CL-37 was examined by comparing cultures grown anaerobically at pH 6.5 in MRS medium containing 220 or $730 \mu \mathrm{g}$ Tween $80 \mathrm{ml}^{-1}$. Organisms grown at the higher Tween 80 concentration and harvested in exponential phase contained a lower amount of detectable cellular lipoteichoic acid, with only minor differences in the amounts of extracellular lipoteichoic acid (Table 3). Organisms that had been in stationary phase for $18 \mathrm{~h}$ contained similar amounts of cellular lipoteichoic acid at both Tween 80 concentrations (Table 3) but the amount of extracellular material was considerably less for cultures grown at the higher Tween 80 concentration. The differences shown by rocket immunoelectrophoresis were supported by the results for the culture fluid titres.

For more detailed studies, a comparison was made of organisms grown anaerobically at 
pH 6.0 in glucose-limited continuous culture at $D=0.05$ and $0.2 \mathrm{~h}^{-1}$ in both MRS and dialysed MRS media, with and without the addition of Tween $80\left(1 \mathrm{mg} \mathrm{ml} \mathrm{m}^{-1}\right)$. Organisms grown in the presence of Tween 80 in MRS or dialysed MRS medium (MRS-D) contained less detectable lipoteichoic acid than organisms grown in its absence (Fig. 2). The results of rocket immunoelectrophoresis on culture fluids indicated that there was more lipoteichoic acid in the culture fluid of organisms grown in dialysed MRS medium in the presence of Tween 80, though no difference was detectable with MRS medium (Fig. 2). These higher levels of extracellular lipoteichoic acid with dialysed medium containing Tween 80 were confirmed by estimating the culture fluid titres which were 12 for each of the cultures grown in its presence but 5 for those grown in its absence.

\section{DISCUSSION}

The relation between the requirement of Tween 80 for growth of $L$. salivarius in batch culture and the $\mathrm{pH}$ of the medium was confirmed and extended by examining cultures of strain IV CL-37 in a chemostat. In complete, as distinct from dialysed, medium under aerobic conditions, growth over the $\mathrm{pH}$ range $5 \cdot 0$ to $7 \cdot 0$ could only be maintained if Tween 80 were present, whereas under anaerobic conditions stable growth could be achieved at $\mathrm{pH} 6.0$ or below in the absence of Tween 80 . As organisms would not grow aerobically in dialysed medium even if Tween 80 were present, a high molecular weight growth factor is probably required for aerobic growth. Our observations further indicate that while organisms will grow under glucose limitation at appropriate $\mathrm{pH}$ without Tween 80 , their morphology is frequently aberrant, with the production of filamentous and branched structures. Studies with Actinomyces viscosus in continuous culture have also shown that morphology is influenced by the growth conditions (van der Hoeven, 1974; Ellwood et al., 1977).

The requirement of Tween 80 for growth under certain conditions could be due to its surfactant properties or it could be acting specifically as a source of oleate. As different Tween esters with laurate, palmitate or stearate were not as effective in supporting batch growth it seems probable that there is a specific requirement for oleate by $L$. salivarius strains. Such specific requirements for unsaturated fatty acids in membrane lipids have been studied in a number of bacteria and relate to the degree of membrane fluidity that is necessary for normal growth (Hauser et al., 1979). If Tween 80 is supplying such a specific need for $L$. salivarius IV CL-37, the requirement is not absolute as growth can occur at lower $\mathrm{pH}$ values in the absence of Tween 80 . However, the aberrant cell morphologies that were frequently obtained under such conditions suggest that normal growth is not occurring because of changes in membrane structure (Hauser et al., 1979).

The effect of Tween 80 on bacterial cell membranes also manifests itself in other ways. With Bifidobacterium bifidum it has been shown that omission of Tween 80 from the medium decreases lipid release from organisms by about 50\% (Veerkamp, 1976). With Streptococcus mutans (Umesaki et al., 1977; Wittenberger et al., 1978) the extracellular glucosyl transferase activity is directly related to Tween 80 concentration in the culture fluid, due to enhancement of enzyme synthesis (Wittenberger et al., 1978).

These observations are relevant to the present studies on the production of lipoteichoic acid by $L$. salivarius. Lipoteichoic acid is present in significant amounts in the culture fluid of streptococci and lactobacilli in association with lipids, proteins and sometimes polysaccharides (Markham et al., 1975; Joseph \& Shockman, 1975; Silvestri et al., 1978), and the amounts of cellular and extracellular lipoteichoic acid are dependent on the growth conditions (Jacques et al., $1979 a, b$ ). The studies with $L$. salivarius in batch culture indicate that a higher Tween 80 content in the medium had little effect on the amount of extracellular lipoteichoic acid formed by exponential phase organisms and that in stationary phase the amount of extracellular lipoteichoic acid was less at the higher Tween 80 value. Organisms in the exponential phase contain less cellular lipoteichoic acid at the higher Tween 80 value, 
and the extracellular lipoteichoic acid detected in stationary phase is probably a reflection of these differences, as it is known that lipoteichoic acid is readily lost from cells in stationary phase (Joseph \& Shockman, 1975).

More definitive evidence on the effect of Tween 80 on lipoteichoic acid formation was obtained from studies on organisms grown in continuous culture under glucose limitation with mean generation times of $3.5 \mathrm{~h}$ and $14 \mathrm{~h}$. Such organisms are growing more slowly than in the exponential phase of batch culture and at rates nearer to those that apply in natural environments (Ellwood, 1976). These experiments, which employed both dialysed and complete medium, indicated an inverse relation between the Tween 80 content of the medium and the amount of detectable cellular lipoteichoic acid at each generation time. With complete medium the amount of extracellular lipoteichoic acid was not influenced by the presence of Tween 80 though in dialysed medium there were greater amounts in the presence of Tween 80 . From the studies on organisms grown in batch and continuous culture it may be concluded that Tween 80 is influencing the membrane properties of the organism in such a way that the amounts of detectable cellular and extracellular lipoteichoic acid may be varied.

This work was supported by the National Health and Medical Research Council of Australia and Public Health Service Research Grants RO1 DEO4174 and RO1 DEO4175 from the National Institute of Dental Research, U.S.A. We thank Rosemary Ann Brown for her excellent technical assistance.

\section{REFERENCES}

Ellwood, D. C. (1976). Chemostat studies of oral bacteria. In Microbiological Aspects of Dental Caries (Special Supplement to Microbiology Abstracts, vol. III), pp. 785-798. Edited by H. M. Stiles, W. J. Loesche \& T. C. O'Brien. Washington, D.C.: Information Retrieval Inc.

Ellwood, D. C., Hunter, J. R. \& Longyear, V. M. C. (1977). Growth of Actinomyces viscosus in a chemostat. Journal of Dental Research 56A, 120.

Fitzgerald, R. G., Fitzgerald, D. B., Adams, B. O. \& DUANY, L. F. (1980). Cariogenicity of human oral lactobacilli in hamsters. Journal of Dental Research 59, 832-837.

Hauser, H., Hazlewood, G. P. \& Dawson, R. M. C. (1979). Membrane fluidity of a fatty acid auxotroph grown with palmitic acid. Nature, London 279, 536-538.

VAN DER Hoeven, J. S. (1974). A slime-producing microorganism in dental plaque of rats selected by glucose feeding: chemical composition of slime elaborated by Actinomyces viscosus NY1. Caries Research 8, 193-210.

JaCQues, N. A., Hardy, L., Campbell, L. K., Knox, K. W., Evans, J. D. \& WiCken, A. J. $(1979 a)$. Effect of carbohydrate source and growth conditions on production of lipoteichoic acid by Streptococcus mutans Ingbritt. Infection and Immunity 26, 1079-1087.

JACQues, N. A., Hardy, L., Knox, K. W. \& Wicken, A. J. $(1979 b)$. Effect of growth conditions on the formation of extracellular lipoteichoic acid by Streptococcus mutans BHT. Infection and Immunity 25, 75-84.

Jacques, N. A., Brown, R. A., Sharpe, M. E. \& FitzGerald, R. J. (1980). Characterization of two strains of cariogenic lactobacilli. Journal of General Microbiology 118, 283-286.

Joseph, R. \& Shockman, G. D. (1975). Synthesis and excretion of glycerol teichoic acid during growth of two streptococcal species. Infection and Immunity 12, 333-338.

de Man, J. C., Rogosa, M. \& Sharpe, M. E. (1960). A medium for the cultivation of lactobacilli. Journal of Applied Bacteriology 23, 130-135.

Markham, J. L., Knox, K. W., WiCKen, A. J. \& Hewett, M. J. (1975). Formation of extracellular lipoteichoic acid by oral streptococci and lactobacilli. Infection and Immunity 12, 378-386.

Packer, N. H. \& Bersten, A. M. (1977). Effect of Tween 80 on the morphology of Trigonopsis variabilis. Journal of General Microbiology 101, 233-236.

Silvestri, L. J., Craig, R. A., Ingram, L. O., HoffmanN, E. M. \& Bleiweis, A. S. (1978). Purification of lipoteichoic acids by using phosphatidyl choline vesicles. Infection and Immunity 22, 107-115.

UMESAKI, Y., KaWAI, Y. \& Mutai, M. (1977). Effect of Tween 80 on glucosyltransferase production in Streptococcus mutans. Applied and Environmental Microbiology 34, 115-119.

VEERKAMP, J.H. (1976). Biochemical changes in Bifidobacterium bifidum var. pennsylvanicus after cell wall inhibition. IX. Metabolism and release of cellular lipids in the presence of antibiotics. Biochimica et biophysica acta 450, 277-287.

Wittenberger, C. L., Beaman, A. J. \& Lee, L. N. (1978). Tween 80 effect on glucosyltransferase synthesis by Streptococcus salivarius. Journal of Bacteriology 133, 231-239. 